\title{
ERP SOFTWARE IMPLEMENTATION - DEFINITION AND KEY COMPONENTS OF IMPLEMENTATION SUCCESS
}

\author{
Thomas Brugger \\ MBA, University of Salzburg Management School, Baumbichlstr. 26, A-5026 Salzburg, Austria
}

\begin{abstract}
The success of an ERP system cannot be easily be determined. Often it is only measured after the implementation itself. But due to the amount of time and money invested into an ERP system it has to be seen and calculated as a business investment. So, its success must be determined over the entire lifespan of usage. Although reliable figures are difficult to determine, the different types and amounts of value created by the utilization or improvement of the ERP system must be determined as specifically as possible. We found that there are three types of success factors building the foundation for this value creation: the project management success, the IT product success and the business product success. The latter can contribute most to value addition, because it works over the whole lifetime of the information system.
\end{abstract}

\section{KEYWORDS}

Enterprise Resource Planning, Software Implementation, Project Management, Critical Success Factors, Corporate Culture

\section{INTRODUCTION}

ERP software forms the backbone of almost all companies today, given they use ERP software solutions to plan and control the use of resources and their business processes (Goyette et. al., 2015). ERP systems are therefore essential in almost all areas of the company (Beheshti et. al, 2014). The implementation of such a system, however, is time-consuming, resource intensive and requires rigor and collaboration from all participants involved.

Interestingly, companies rarely investigate in retrospect how successful the implementation actually was in business terms, i.e. as an investment (Stein, 1999). Significant amounts of time and money are invested in many ERP implementations, without checking their contribution to business success and value creation of the respective companies in the long run (Hajli et. al., 2015). Furthermore, the term "success" and its underlying criteria has not yet been sufficiently defined in the context of ERP implementations. Important aspects of the ERP implementation in the sense of an essential investment of a company are ignored. To resolve this shortcoming is the starting point of this paper.

\section{RESEARCH METHODS}

During analysis leading to above assessment, we found that only few researchers have defined the success of ERP implementation with long-term business perspective, including key components of the implementation success leading to economic success for the company. Identifying these components for implementation, namely the increase of organizational and economic performance of the organization, and who can drive this in the project and beyond, is therefore a critical issue to be discussed.

The methodology of this research consists of three major parts: first a systematic literature review (confirmation paper) which sets the base for, second, exploratory interviews with managers and consultants and experts in the field of ERP implementation. In a third step a qualitative study with professionals in the field should confirm and refine findings. The systematic literature review searches for major issues of ERP implementation, investment calculation and possible benefits of ERP systems from an academic point of view. 
From this analysis, exploratory interview questions will be derived from literature and discussed with expert interview partners to derive further aspects from a business point of view and to refine the research and hypothesis. The qualitative study will test the research model with key Stakeholders in German and European companies actually running newly implemented systems or implementing ERP systems at present.

\section{DEFINITION OF ERP IMPLEMENTATION SUCCESS}

An ERP implementation usually does not only take several years, it is also extremely cost-intensive. Usually, only external consultant costs as well as the costs for hardware and software are considered in the project costs. However, a full cost calculation for the project should also include the salary costs of the employees participating in the project and all other resources incurred, increasing total investment to highly considerable levels.

Due to its immense cost - many companies regard an ERP project as the largest project in a decade - and above all due to the considerable effects of the ERP implementation on the entire company, such a project must be regarded as an essential company investment and accordingly be subject to a detailed investment calculation (Marbert et. al., 2001). Such project would only be successful if it produced net value added, running up to the end of its useful life (Scheurer and Ribeiro, 2012a, Umble et. al., 2003). Only then will the investment pay off and the company should decide in favor of it (Wang et. al., 2008). Otherwise, alternative investment opportunities should be seized. Such economic considerations allow companies to survive and prosper.

By contrast, most literature speaks of the success of an ERP implementation when the selected software has been successfully implemented into the company's IT landscape and is ready for use by employees, i.e. soon after go-live (Hasan et. al., 2018). Compared with a production plant or another investment scenario, this would mean: "The production plant is up and running without errors, so the investment is successful." However, this would not include a review of the benefits produced, which are part of a good business case.

As we have established in our research, this economically necessary consideration is largely omitted in the vast majority of cases of ERP implementations. Only some companies perform a detailed business case prior to the start of the project, based on investment and how much money they intend to save with the ERP. However reliable figures for this are difficult to determine. ERP systems are not directly involved in the value creation for a company (Osnes et. al., 2018). Most companies will not be able to determine reliable figures, especially in the planning phase. But the more concrete and detailed the management deals with these questions, the more precisely it can formulate requirements for the future system and the overall project.

It must be precisely defined how and in which areas the ERP system is to contribute to value creation (Scheurer and Ribeiro, 2012b). After all, business success ultimately depends not only on the design of the system but also on the overall implementation project. First of all, we define the success of the implementation of an ERP system as follows:

An ERP implementation is successful if not only the software implementation, but also the overall project has been completed in such a way that the use of the system can achieve greater added value in the company in the future than without. Or in short: The ERP system must be implemented in such a way that the planned added value can be fully realized!

\section{KEY COMPONENTS OF IMPLEMENTATION SUCCESS}

Having defined implementation success, it must be clarified which essential components it consists of. This shows three major components contributing to success: project management success, IT product success and business product success:

\subsection{Project Management Success - Magic Triangle}

The success of project management is the most thoroughly investigated component in relevant literature. Not only for the implementation of ERP projects, but also many other types of projects rely on this success measure, also known as the „magic triangle“ (Leikep, 2019). It consists of three parameters: cost, time and performance 
or quality (Markus et.al., 2000). The parameters are interdependent, so that a change in one parameter must be offset by changes in one or both of the other parameters.

Before the project starts, targets are set for all three parameters. Almost immediately after the end of the project, i.e. after the commissioning of the software, it can then be determined whether this success factor has been adhered to (Talluri and A Vasudeva, 2019). The project management success is particularly important for the success of the ERP system as a whole because two essentials are based here: On the one hand, the potential technical performance of the system is determined, i.e. the theoretically possible added value (Simon and Noblet, 2012). On the other hand, a significant part of the value destruction caused by the ERP system is determined with direct incurred costs.

\subsection{IT Product Success - Requirement Fit}

A second component of the implementation success is the IT product success. It shows to which extent the new ERP system actually meets the original business requirements. It has to be proven that the necessary efficiency and flexibility is granted over the entire service life of the system (Peng and Nunes, 2016).

While the requirements for the system at the time of project start are quite precise, it is usually difficult to predict which requirements the ERP software will have to meet in the course of its operating life. If one already considers a project duration of several years and in addition a considerable operating lifetime, it becomes clear that with the decision for a product and its arrangement, considerable uncertainty exists regarding its fit with future requirements. Therefore, the focus on future requirements should already be set and continued to be adapted during the project planning and implementation.

\subsection{Business Product Success - Value Creation}

However, the essential contribution to the success of an ERP implementation is the success of the business product, which is shown in its contribution to the added value. This point is not only dependent on the system itself, but also on accompanying factors, e.g. what users can do with the system's capabilities. Do they actually embrace information and possibilities provided by the system to realize the hoped-for savings, optimization or growth potential (Markus et. al., 2000)?

This is normally determined at two critical points: The first, still within the implementation phase, consists of the self-critical, unprejudiced and future-oriented reorganization of business processes. This is often done too hesitantly and with little courage and determination, so that the company remains in the past instead of taking a step into the future.

The second critical point is the use of the system in practice (Osnes et. al., 2018). Acceptance and mastery of the systems by users and corresponding nurturing by corporate culture are important determinants. The information and data from the new ERP system have to be actively used by the employees to bring about changes and innovation, thus producing added value (DeLone and McLean, 1992). Many companies focus their training activities on the system only and underestimate that also new culture and innovation should be implemented in the company.

\section{PRECONDITIONS FOR VALUE CREATION}

An essential part of the added value that can be generated by an ERP system is not automatically realized by the software but must be actively generated by the people working with the system. Our research indicates three essential prerequisites that must be fulfilled:

\subsection{Data Availability and Transparency}

First of all, an ERP system must be configured and designed in such a way that it provides the necessary data for all relevant employees. These must be sufficiently up-to-date and transparent and should be able to be prepared according to the respective demands and requirements of the employee (Markus et. al., 2000). Ideally, no programming is necessary for this; each employee should be able to pull up individual analysis as needed 
and beyond, to perform day to day business but also to investigate innovative considerations (Govindaraju, Dwipayana, Salamah, 2018).

Already during the planning and implementation of the system, special value should be attached to this point. The software has to be configured in such a way that data is available transparently, real time and analyses can be prepared easily and flexibly. This should not only be done for current business processes but be considered as far as possible for future requirements.

\subsection{User Acceptance}

An essential success factor is the acceptance of the system by its users (Muscatello and Chen, 2008). If they are reluctant to use the software or are poorly trained on it and would not embrace the new possibilities, the ERP system will not be able to add optimal value to the company (DeLone and McLean, 2003, Gazaleh, Abdallah and Zabadi, 2019). Available data would then remain unused.

During the course of the project, intensive training should take place not only on how the system works, but also on the advantages of the system in terms of content and its effects on the entire business process and opportunities (Wenrich and Ahmad, 2009, Chadhar and Daneshgar, 2018). It should be clear to the users which possibilities the new system offers and how they can leverage its potential.

\subsection{Cultural Change}

Jointly with a distinctive effort for user acceptance, a change in the entire corporate culture is also necessary. ERP systems are designed to identify inefficiencies and develop new opportunities. However, these can only be changed or realized if there is a corresponding culture of change in the company. If the employees are critical or rejecting changes, they will not prevail, and the possibilities of the ERP system remain unused.

An ERP system can carry out routine tasks independently and thus opens up new scope for employees. If these free capacities are not (or cannot be) used accordingly because users oppose to them, the value creation potential of a new ERP system remains untapped (Ifinedo and Olsen, 2014). It therefore requires much more than just the implementation of software to successfully introduce an ERP system. Above all, it requires a profound cultural change for all employees in the company, not just for the immediate users (Umble et. al., 2003).

\section{CONCLUSION}

We found that the commonly used definition of ERP implementation success is not sufficient. The success cannot be measured at the point in time when the software is set productive. For a large investment, such as the implementation of a new ERP system, the essential question is, how value creation by means of the new system can be fostered to greatly exceed and offset the costs of its implementation and operation.

It is shown that value creation is not only dependent on the technical operating system and the processes which are redesigned. Value creation is largely dependent on what the people make of the opportunities the software and processes provide them with. So, users are in the clear focus of implementation success, e.g.: Are users harvesting the possibilities the ERP-system is offering? Are they working in a company culture that is fostering change, taking risks and making mistakes?

The ERP-system is only creating little value in itself. Much of the supposed value is created by people. So, implementation success mainly depends on enabled people who work with the ERP-system and who are convinced that it is also good for themselves, not only for the company. 


\section{REFERENCES}

Beheshti, H. M., Blaylock, B. K., Henderson, D. A., Lollar, J. G., 2014. Selections and critical success factors in successful ERP implementation. Competitiveness Review, Vol. 24, No. 4, pp. 357-375.

Chadhar, M., Daneshgar, F., 2018. Organizational Learning and ERP Post-implementation Phase: A Situated Learning Perspective. Journal of Information Technology - Theory and Application, Vol. 19, No. 1, pp. 138-156.

DeLone, W. H., McLean, E. R., 1992. Information systems success: The quest for the dependable variable. Information Systems Research, Vol. 3, No. 1, pp. 60-95.

DeLone, W. H., McLean, E. R., 2003. The DeLone and McLean model of information system success: A ten-year update. Journal of Management Information Systems, Vol. 19, No. 4, pp. 9-30.

Ghazaleh, M. A., Abdallah, S., Zabadi, A., 2019. Promoting successful ERP post-implementation: a case study. Journal of Systems and Technology, Vol. 21, No. 3. pp. 325-346.

Govindaraju, R., Dwipayana, N., Salamah, S., 2018. IT Governance and ERP Post-Implementation: Analyzing the impact of IT business alignment and IT benefits management on ERP operation and enhancement. International Journal of Technology, Vol. 9, No. 3, pp. 578-588.

Goyette, S., Cassivi, L., Courchesne, M., Elia, E., 2015. The ERP post-implementation stage: a knowledge transfer challenge. International Journal of Information Systems and Project Management, Vol. 3, No. 2, pp. 5-19.

Hajli, M., Sims, J. M., Ibragimov, V., 2015. Information Technology (IT) Productivity Paradox in the $21^{\text {st }}$ Century. International Journal of Productivity and Performance Management, Vol. 64, No. 4., pp. 457-478.

Hassan, M., Jabar, M. A., Sidi, F., Jusoh, Y. Y., Abdullah, S., 2018. Critical Success Factors and their Influence in ERP Implementation Success of Organizational Performance. Acta Informatica Malaysia, Vol. 2, No. 1, pp. 12-16.

Ifinedo, P., Olsen, D. H., 2014. An Empirical Research on the Impacts of organizational decisions' locus, tasks structure rules, knowledge, and IT functions' value on ERP system success. International Journal of Production Research, Vol. 53, No. 8, pp. 2554-2568.

Leikep, S., 2019. Jetzt kommt das agile Management. Produktion, No. 9, pp. 8-9.

Marbert, V. A., Ashok S., Venkataramanan, M. A., 2001. Enterprise Resource Planning: Common Myths Versus Evolving Reality. Business Horizons, Vol. 44, No. 3, pp. 69-76.

Markus, M. L. Axline, S., Petrie, D., Tanis, C., 2000. Learning from Adopters' Experiences with ERP - Successes and Problems. Journal of Information Technology, Vol. 15, No. 4, pp. 245-265.

Muscatello, J. R. and Chen, I. J., 2008. Enterprise Resource Planning (ERP) Implementations: Theory and Practice. International Journal of Enterprise Information Systems, Vol. 4, No. 1, pp. 63-77.

Osnes, K. B., Olsen, J. R., Vassilakopoulou, P., Hustad, E., 2018. ERP Systems in Multinational Enterprises: A literature Review of Post-implementation Challenges. Procedia Computer Sciences, Vol. 138, pp. 541-548.

Peng, G. C., Nunes, M., 2016. Establishing an evidenced-based 9D evaluation approach for ERP post-implementation. Industrial Management \& Data Systems, Vol. 117, No. 2, pp. 398-424.

Scheurer, S., Ribeiro, M., 2012a. Projektmanagement unter Unsicherheit - Die tägliche Herausforderung im Projekt, Teil 1. Projektmanagement aktuell, No. 1, pp. 27-31.

Scheurer, S., Ribeiro, M., 2012b. Projektmanagement unter Unsicherheit - Die tägliche Herausforderung im Projekt, Teil 2. Projektmanagement aktuell, No. 2, pp. 48.

Simon, E., Noblet, J. P., 2012. Integrating ERP into the Organization: Organizational Changes and Side-Effects. International Business Research, Vol. 5, No. 2, pp. 51-58.

Stein, T., 1999. ROI: Making ERP add up. Information week, No. 735, pp. 59-63

Talluri, S. K., Reddy, A V., 2019. Critical success factors of ERP implementations in SMEs. Journal of Project Management, Vol. 4, No. 4, pp. 267-280.

Umble, E. J., Haft, R. R., Umble, M. M., 2003. Enterprise resource planning: Implementation procedures and critical success factors. European Journal of Operational Research, Vol. 146, No. 2, pp. 241-257.

Wang, E. T. G., Shih, S. P., Jiang, J. J., Klein, G., 2008. The consistency among facilitating factors and ERP implementation success: A holistic view of fit. Journal of Systems and Software, Vol. 81, No. 9, pp. 1609-1621.

Wenrich, K., Ahmad, N., 2009, Lessons learned during a decade of ERP experience: A case study. International Journal of Enterprise Information Systems, Vol. 5, No. 1, pp. 55-73. 